\title{
Incremental validity of work-related sense of coherence in predicting work wellness
}

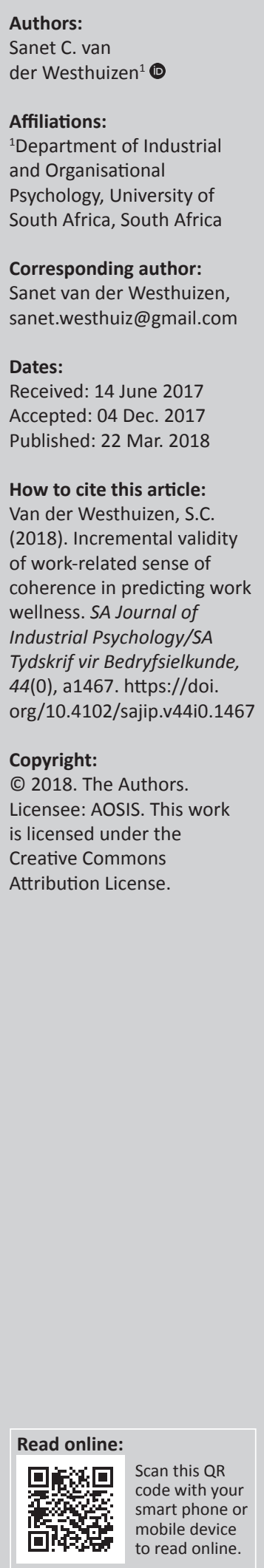

Orientation: Sense of coherence and, more recently, work-related sense of coherence are regarded as significant variables in promoting the management of employees' wellness in modern organisations.

Research purpose: The aim of the present study was to investigate whether work-related sense of coherence, as a context-specific application of sense of coherence, provides incremental validity over and above sense of coherence in explaining indicators of work wellness.

Motivation for the study: It is important to know if the context-specific, work-related sense of coherence is a better predictor of work wellness in comparison with general sense of coherence in order to guide interventions aimed at the development and enhancement of employees' wellness.

Research approach, design and method: A cross-sectional survey design was used with a convenience sample $(N=734)$ of part-time and full-time working adults completing an online module at a distance education institution. A biographical questionnaire, the Work-related sense of coherence (SoC) Questionnaire, the Orientation to Life Questionnaire, the Fatigue Scale and Work Engagement Scale were administered. Hierarchical multiple regression analyses were performed to achieve the objective of the study.

Main findings: Work-related sense of coherence displayed incremental validity over and above that of sense of coherence in predicting work engagement and fatigue. However, sense of coherence was a stronger predictor of fatigue, while work-related sense of coherence was a stronger predictor of work engagement.

Practical managerial implications: In planning interventions to address the work engagement or fatigue of employees, work-related sense of coherence could be used as a practical indicator of coherent work experiences, especially in predicting work engagement.

Contribution: The results of the study should provide new insight into the shared variance between work-related sense of coherence and sense of coherence. The results indicated that the factors are interrelated but independent and that work-related sense of coherence adds incremental variance in predicting work engagement and fatigue in the context of work.

\section{Introduction}

More than three decades ago, Antonovsky (1987, p. 154) concluded that it is 'unrealistic to think that a working environment totally free of stressors could be created; people will always have to

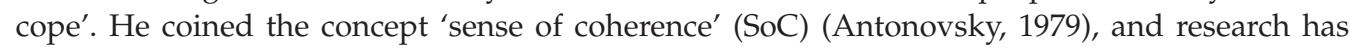
consistently shown that employees with a strong SoC cope more efficiently with stressors in the working environment (Feldt, 1997; Van der Colff \& Rothmann, 2009) and may even experience less risk of developing symptoms of ill-health relating to burnout over a 10-year period (Kalimo, Pahkin, Muthanen \& Topipinen-Tanner, 2003). Recently, Bauer and Jenny (2007) proposed a context-specific application of SoC in the working environment, namely work-related sense of coherence (Work-SoC). In order to determine the theoretical and practical value of Work-SoC, Jenny, Bauer, Vinje, Vogt and Torp (2017) urged that the relationship between Work-SoC and SoC should be explored empirically. There currently appears to be a paucity of research investigating the context-specific Work-SoC in relation to general SoC in the context of work. The purpose of this research was therefore to determine whether Work-SoC provides incremental validity above and beyond that of SoC in predicting work engagement and fatigue as indicators of work wellness.

\section{Sense of coherence}

Antonovsky (1979) defined SoC as a general orientation relating to the degree to which an individual perceives stimuli from the environment to be consistent or understandable 
(comprehensibility); the degree to which the individual believes that resources are available to cope with demands (manageability); and the degree to which the individual perceives it worthwhile to address the demands (meaningfulness).

The direct, moderating and mediating role of SoC in relation to organisational outcomes and work wellness indicators has been researched extensively (for an overview of a few studies, see Jenny et al., 2017; Mayer \& Krause, 2011). Specifically, SoC has been found to be negatively associated with burnout (Fourie, Rothmann \& Van de Vijver, 2008; Van der Colff \& Rothmann, 2009), positively associated with work engagement (Fourie et al., 2008; Vogt, Hakanen, Jenny \& Bauer, 2016) and to be moderating the effects of detrimental work conditions on health outcomes (Jenny et al., 2017). Conversely, Antonovsky (1987) also proposed that working processes could have both detrimental and health-promoting consequences for an employee's SoC (Antonovsky, 1987). Numerous research studies have since confirmed that SoC is indeed influenced by a number of work and organisational variables (Jenny et al., 2017).

\section{Work-related sense of coherence}

Work-related sense of coherence has been proposed as a context-specific application of SoC in the working environment (Bauer \& Jenny, 2007). Similar to the definition of SoC, Work-SoC is defined 'as the perceived comprehensibility, manageability and meaningfulness of an individual's current work situation' (Vogt, Jenny \& Bauer, 2013, p. 1).

The perception of comprehensibility can be described as the degree to which information from the environment makes sense at a cognitive level, and the employee experiences the stimuli as consistent, clear, structured and thus predictable (Antonovsky, 1987; Vogt et al., 2013). Comprehensibility at work is generally influenced by enabling the employee to see his or her role in achieving the overall goals of the organisation, a sense of job security and the experience of shared values and identifying with a group at work in which clear normative expectations exist (Antonovsky, 1987). Even though stressors might be seen to be ordered, they can still pose demands, and comprehensibility on its own is therefore not sufficient.

Manageability can be described as the degree to which employees perceive resources to be available, to either themselves or other reliable individuals in the working environment and that these resources are adequate to meet the demands (Antonovsky, 1987; Vogt et al., 2013). Manageability in the work environment may be influenced by 'an appropriate overload-underload balance' (Antonovsky, 1987, p. 161). Employees must be convinced that the problems facing them are legitimate and applicable to their work; that they have the necessary knowledge, skills, material and equipment to address the task at hand; that their potential is fulfilled; and that support is available from legitimate others in the working context (Antonovsky, 1987).
Antonovsky (1987, p. 156) further proposed that employees must actually 'care to cope'. Meaningfulness, as the third dimension of Work-SoC, therefore, relates to the degree to which employees regard stressors and demands or situations at work as worthy of investing energy in and worthy to commit to or become involved in (Antonovsky, 1987; Vogt et al., 2013). Meaningfulness relates to the degree to which employees feel a sense of ownership in their work, the degree to which they can participate in decision-making and the degree to which they may experience discretionary freedom in their task and work environment (Antonovsky, 1987).

Work-related sense of coherence has been found to be negatively related to job demands and burnout (Vogt et al., 2013) but positively related to job resources (Vogt, Jenny, Fülleman, Inaunen \& Bauer, 2012), an employee-directed leadership style (Brossing \& Sjovall, 2010), work engagement (Van der Westhuizen \& Ramasodi, 2016; Vogt et al., 2013) and the perception that the organisational climate is supportive of employee health and well-being (Zweber, 2014). As a personal resource, Work-SoC can also act as a mediator in the work-health relationship, and Vogt et al. (2013) found that Work-SoC partially mediated both the relationship between job demands and exhaustion and the relationship between job resources and work engagement. The mediating effect, however, was stronger in the process that leads from job resources to work engagement (Vogt et al., 2013). One can therefore expect Work-SoC to change when work characteristics (such as job demands, job resources, leadership style and organisational climate) vary (Vogt et al., 2013) and to be related to employees' work wellness.

Vogt, Bauer and Jenny (2014) proposed that Work-SoC can be used as a practical screening of employees' perception of the health-promoting quality of their work situation. This assessment is thus useful for planning, managing and evaluating health-related interventions in a working environment.

\section{Work-related sense of coherence and sense of coherence}

Vogt et al. (2013) proposed that Work-SoC, as a contextspecific application of SoC, may be more dynamic and sensitive to changes in the work context than general SoC. Eberz, Becker and Antoni (2011) investigated both SoC and Work-SoC in relation to work-related stress in a sample of pastors' secretaries $(N=93)$. Evidence from this study suggests that Work-SoC explains incremental variance and seems to be a stronger predictor of work-related stress than SoC (Eberz et al., 2011). These findings seem to support the proposition that Work-SoC may serve as a better predictor of employees' wellness in the work context in comparison to the measurement of general SoC. A recent call has been raised by Jenny et al. (2017) that the relationship between Work-SoC and SoC should be explored empirically. However, the findings of Eberz et al. (2011) have not yet been corroborated by any other studies. It is therefore important to determine if Work-SoC explains incremental variance above that of SoC 
in predicting work wellness. That way one can determine if the context-specific application is more effective in predicting employee wellness in the work context in comparison to the measurement of general SoC. The findings of the current study could guide management in planning and implementing interventions aimed at increasing the WorkSoC or SoC of employees in order to address fatigue (as a subdimension of burnout) and work engagement in the organisation.

Taking previous research into account, the following hypotheses were formulated for this study:

$\mathbf{H}_{1}$ : Work-related SoC provides incremental validity over and above $\mathrm{SoC}$ in predicting work engagement.

$\mathbf{H}_{2}$ : Work-related SoC provides incremental validity over and above $\mathrm{SoC}$ in predicting fatigue.

\section{Research design Research approach}

This study followed a quantitative, descriptive approach and used a cross-sectional survey design in order to gather data. According to Zikmund (2003), a cross-sectional design is used when data from numerous people are collected at a single point in time.

\section{Research method}

\section{Research participants}

The population included part-time and full-time working adults registered for a research methodology module at honours level at a distance education institution $(N=1487)$. Students were requested to complete the assessments online on their module site. A convenience sample of $N=837$ responded to the invitation (response rate of approximately $56 \%$ ) and $n=734$ correct response sets could be extracted. The characteristics of the participants are detailed in Table 1.

Table 1 indicates that the sample group consisted of $33.7 \%$ male and $66.2 \%$ female participants. Most of the participants spoke English (19.9\%), isiZulu (13.5\%) and Afrikaans (12.9\%). The majority of the participants were either single $(47.7 \%)$ or married $(42 \%)$ and had a 3 -year degree $(73.8 \%)$ or a 4 -year degree $(20.8 \%)$ as a qualification. The age of the participants varied from 20 to 62 years (mean age $=34$ years) and work experience ranged from a few months to 42 years (mean of 7 years' experience) with most participants being employed on a full-time basis $(91.1 \%)$.

\section{Measuring instruments}

In order to measure the variables on the study, the participants were required to complete a biographical section, the WorkSoC Questionnaire (nine items), the Orientation to Life Questionnaire (OLQ; six items), the Fatigue Scale (five items) and the Utrecht Work Engagement Scale (UWES-9).

The Work-SoC Questionnaire (Bauer, 2010; Bauer, Vogt, Inaunen \& Jenny, 2015) consists of nine items that measure three
TABLE 1: Characteristics of participants in the sample $(n=734)$.

\begin{tabular}{|c|c|c|c|}
\hline Item & Category & $\%$ & Frequency \\
\hline \multirow[t]{3}{*}{ Gender } & Male & 33.7 & 247 \\
\hline & Female & 66.2 & 486 \\
\hline & Missing & 0.1 & 1 \\
\hline \multirow[t]{12}{*}{ Language group } & Afrikaans & 12.9 & 95 \\
\hline & English & 19.9 & 146 \\
\hline & isiNdebele & 1.8 & 13 \\
\hline & isiXhosa & 8.2 & 60 \\
\hline & isiZulu & 13.5 & 99 \\
\hline & Sepedi & 9.0 & 66 \\
\hline & Sesotho & 6.9 & 51 \\
\hline & Setswana & 9.1 & 67 \\
\hline & isiSwati & 3.7 & 27 \\
\hline & Thsivenda & 4.0 & 29 \\
\hline & Xitsonga & 4.8 & 35 \\
\hline & Missing & 6.3 & 46 \\
\hline \multirow[t]{6}{*}{ Marital status } & Single & 47.7 & 350 \\
\hline & Separated & 0.7 & 5 \\
\hline & Divorced & 4.1 & 30 \\
\hline & Married & 42 & 308 \\
\hline & Widowed & 1.1 & 8 \\
\hline & Engaged & 4.5 & 33 \\
\hline \multirow[t]{6}{*}{ Qualification } & 3-year degree & 73.8 & 542 \\
\hline & 4-year degree & 20.8 & 153 \\
\hline & Honours & 3.7 & 27 \\
\hline & Master's & 1.1 & 8 \\
\hline & Doctorate & 0.3 & 2 \\
\hline & Missing & 0.3 & 2 \\
\hline \multirow[t]{2}{*}{ Employment status } & Part-time & 8.9 & 65 \\
\hline & Full-time & 91.1 & 669 \\
\hline
\end{tabular}

subscales, namely comprehensibility (four items), manageability (two items) and meaningfulness (three items). The work-related sense of coherence is scored on a 7-point frequency rating. Vogt et al. (2012) and Bauer et al. (2015) reported a Cronbach alpha of 0.83 and a test-retest correlation (1-year interval) of 0.53 and that the scale had a three-factor structure. Vogt et al. (2013) confirmed the three-factor structure of the questionnaire. Zweber (2014) as well as Van der Westhuizen and Ramasodi (2016) also found that a threefactor structure fitted the data better than a one-factor structure. Vogt et al. (2013) showed that the questionnaire functioned equally well for different gender and age groups, for employees with lower and higher levels of education and for employees with or without a leadership position. The questionnaire's factor structure was also invariant across time.

The Orientation to Life Questionnaire (six items) (Van Schalkwyk \& Rothmann, 2008) is a shortened version of the 29-item OLQ developed by Antonovsky (1987). Van Schalkwyk and Rothmann (2008) confirmed the three-factor structure of the OLQ-6 measuring comprehensibility (two items), manageability (two items) and meaningfulness (two items). The OLQ-6 also had a Cronbach alpha coefficient of 0.73 in the study by Van Schalkwyk and Rothmann (2008) and 0.86 in the study by Barnard and Muller (2012).

The Fatigue Scale (five items) (Asiwe, Jorgensen \& Hill, 2014) is a subscale of the 17-item Burnout scale that was developed for a South African context, measuring cognitive weariness, 
fatigue and emotional exhaustion or withdrawal. This fatigue subscale is closely related to the exhaustion subscale of other burnout measures like the Maslach burnout inventory: General survey (Schaufeli, Leiter, Maslach \& Jackson, 1996) and the Oldenburg Burnout Inventory (OLBI) (Demerouti, Bakker, Vardakou \& Kantas, 2003). Asiwe et al. (2014) reported a Cronbach alpha coefficient of 0.85 for this subscale.

The Utrecht Work Engagement Scale (UWES) (nine-item) (Schaufeli, Salanova, Gonzáles-Romá \& Bakker, 2002) was used to measure work engagement in this study. The UWES measures vigour, dedication and absorption as subdimensions of work engagement. Schaufeli, Bakker and Salanova (2006) reported Cronbach alpha values ranging from 0.65 to 0.79 for these subdimensions.

\section{Research procedure and ethical considerations}

Participants were requested to complete the assessment online. Before completing the assessments, participants had to indicate that they consented to the possible use of their data for research purposes. They were also assured that their personal information would not be used in any way other than to report on the results of the research in group format.

\section{Statistical analyses}

Structural equation modelling with Mplus 7.4 (Muthén \& Muthén, 1998-2016) was used to validate the measuring instruments and test the structural model. The items were defined as continuous, and the robust maximum likelihood (MLR) was used as the estimator to account for the skewness of the data. The following fit indices were used in this study: (1) absolute fit indices, including the chi-square statistic and the root mean square error of approximation (RMSEA) and (2) incremental fit indices, including the Tucker-Lewis Index (TLI) and the Comparative Fit Index (CFI) (Hair, Black, Babin \& Anderson, 2010). The following cut-off scores were applied: CFI and TLI $\geq 0.90$ (Hair et al., 2010) and RMSEA $<0.05$ to indicate good fit. However, values as high as 0.08 can be seen to represent reasonable errors of approximation (Hair et al., 2010). The composite reliability of the measuring instruments was calculated by using Raykov's formula (Raykov, 1997). SPSS 24.0 (SPSS, 2016) was used to determine the descriptive statistics, correlation between variables and regression analysis. Hierarchical linear regression analyses were conducted to determine the degree of incremental variance that Work-SoC predicts over and above the variance of SoC. Cohen's (1992, p. 157) practical significant cut-off points for the correlation coefficient $(r \geq 0.30=$ medium effect; $\geq 0.50=$ large effect) and regression $\left(f^{2}=R^{2} / 1-\right.$ $R^{2} ; \geq 0.02=$ small effect, $\geq 0.15=$ medium effect, $\geq 0.35=$ large effect) were used to determine the effect size. Statistical significance was set at $p<0.05$.

\section{Ethical consideration}

Ethical clearance for the study was granted by the hosting university.

\section{Results Validity of the measuring instruments}

In order to determine the validity of the measuring instruments, the measurement model was tested by means of structural equation modelling. The results are presented in Table 2. Several competing models were compared in the analyses. Model 1 was specified with Work-SoC consisting of three factors (comprehensibility - four items; manageability two items; meaningfulness - three items) (Bauer et al., 2015; Van der Westhuizen \& Ramasodi, 2016), SoC consisting of three factors (comprehensibility - two items; manageability two items; meaningfulness - two items) (Barnard \& Muller, 2012; Van Schalkwyk \& Rothmann, 2008); fatigue consisting of one factor (five items) (Asiwe et al., 2014); and work engagement consisting of three factors (vigour - three items; dedication - three items; absorption - three items) (Schaufeli et al., 2006). Model 1 was not positive definite as the meaningfulness dimension of SoC displayed a negative residual variance. Model 2 followed the same template as model 1, but SoC was specified to consist of one factor (six items). Model 3 followed the template of model 2 but specified Work-SoC consisting of three factors (comprehensibility - three items; manageability - three items; meaningfulness - three items) (Bauer et al., 2015). Model 4 followed the template of model 3 but specified Work-SoC to consist of one factor (Bauer et al., 2015). Model 5 followed the template of model 3 but specified work engagement to consist of only the two core factors, namely vigour (three items) and dedication (three items) (Schaufeli \& Bakker, 2004). No additional modifications were done and further analyses were based on model 5 .

Table 2 indicates that the measurement model as specified in model 5 displayed an acceptable fit (with fit indices CFI and TLI $>0.90$ and RMSEA below 0.08).

The descriptive statistics, reliability of the measuring instruments and the correlation between the variables are indicated in Table 3.

Table 3 indicates that all subscales and scales displayed an acceptable level of composite reliability $(>0.70)$, except for the subscale of comprehensibility $(p=0.66)$. In line with the recommendations of Bauer et al. (2015) and Schaufeli et al. (2006), only the total scales of Work-SoC and work engagement were used in subsequent analysis. Relationships between Work-SoC and SoC on the one hand and fatigue and work engagement on the other hand were all practically significantly related (large effect) and in the expected direction.

TABLE 2: Fit statistics for the competing measurement models.

\begin{tabular}{llllllll}
\hline Model & \multicolumn{1}{c}{$\boldsymbol{\chi}^{2}$} & $d f$ & $\boldsymbol{p}$ & $\mathrm{CFI}$ & TLI & RMSEA & RMSEA 90\% Cl \\
\hline Model 1 & - & - & - & - & - & - & - \\
Model 2 & 1071.77 & 365 & 0.00 & 0.90 & 0.89 & 0.05 & $0.05-0.06$ \\
Model 3 & 1071.77 & 365 & 0.00 & 0.90 & 0.89 & 0.05 & $0.05-0.06$ \\
Model 4 & 1196.49 & 368 & 0.00 & 0.88 & 0.87 & 0.06 & $0.05-0.06$ \\
Model 5 & 852.84 & 288 & 0.00 & 0.91 & 0.90 & 0.05 & $0.05-0.06$ \\
\hline
\end{tabular}

$\chi^{2}$, chi-square; $d f$, degrees of freedom; $p$, statistical significance; $\mathrm{CFI}$, comparative fit index; $\mathrm{Cl}$, confidence interval; TLI, Tucker-Lewis fit index; RMSEA, root mean square error of approximation. 
TABLE 3: Descriptive statistics, composite reliabilities and Pearson correlations of the subscales and scales of Work-SoC, SoC, fatigue and work engagement.

\begin{tabular}{|c|c|c|c|c|c|c|c|c|c|c|c|}
\hline Subscale & Mean & Standard deviation & $p$ & 1 & 2 & 3 & 4 & 5 & 6 & 7 & 8 \\
\hline 1. Comprehensibility & 5.38 & 1.18 & 0.66 & - & - & - & - & - & - & - & - \\
\hline 2. Manageability & 5.40 & 1.17 & 0.72 & $0.61 \dagger$ & - & - & - & - & - & - & - \\
\hline 3. Meaningfulness & 5.60 & 1.29 & 0.84 & $0.47 \ddagger$ & $0.57 \ddagger$ & - & - & - & - & - & - \\
\hline 4. Work-SoC & 5.46 & 1.01 & 0.90 & $0.83 \dagger$ & $0.86+$ & $0.82+$ & - & - & - & - & - \\
\hline 5. SoC & 5.26 & 1.12 & 0.79 & $0.35 \dagger$ & $0.46 \dagger$ & $0.49 \ddagger$ & $0.52 \ddagger$ & - & - & - & - \\
\hline 6. Fatigue & 3.17 & 1.09 & 0.81 & $-0.36 \dagger$ & $-0.45 \dagger$ & $-0.44 \dagger$ & $-0.50 \ddagger$ & $-0.57 \$$ & - & - & - \\
\hline 7. Vigour & 5.13 & 1.21 & 0.74 & 0.28 & $0.40 \dagger$ & $0.56 \ddagger$ & $0.50 \ddagger$ & $0.48 \dagger$ & $-0.55 \$$ & - & - \\
\hline 8. Dedication & 5.40 & 1.44 & 0.87 & $0.31 \dagger$ & $0.42 \dagger$ & $0.70 \%$ & $0.57+$ & $0.49 \dagger$ & $-0.48 \dagger$ & $0.74 \ddagger$ & - \\
\hline 9. Work engagement & 5.26 & 1.24 & 0.89 & $0.32 \dagger$ & $0.44 \dagger$ & $0.69 \ddagger$ & $0.58 \div$ & $0.52 \ddagger$ & $-0.55 \dagger$ & $0.92 \%$ & 0.95 \\
\hline
\end{tabular}

$\dagger$, Correlation is of practical significance, medium effect $(r>0.3)$; $\uparrow$, Correlation is of practical significance, large effect $(r>0.5)$.

Work-SoC, Work-related sense of coherence; SoC, sense of coherence.

\begin{tabular}{|c|c|c|c|c|c|c|c|c|c|c|c|}
\hline \multirow[t]{2}{*}{ Variable } & \multirow[t]{2}{*}{ Model } & \multicolumn{2}{|c|}{ Unstandardised coefficients } & \multirow{2}{*}{$\begin{array}{c}\text { Standardised } \\
\text { coefficients: Beta }\end{array}$} & \multirow[t]{2}{*}{$t$} & \multirow[t]{2}{*}{$p$} & \multirow[t]{2}{*}{$F$} & \multirow[t]{2}{*}{$R$} & \multirow[t]{2}{*}{$R^{2}$} & \multirow[t]{2}{*}{$\Delta R^{2}$} & \multirow[t]{2}{*}{$f^{2}$} \\
\hline & & Beta & SE & & & & & & & & \\
\hline \multirow{10}{*}{$\begin{array}{l}\text { Work } \\
\text { engagement }\end{array}$} & Constant & 2.22 & 0.19 & - & 11.69 & 0.00 & 267.25 & 0.52 & 0.27 & 0.27 & 0.37 \\
\hline & SoC & 0.58 & 0.04 & 0.52 & 16.35 & $0.00 *$ & - & - & - & - & - \\
\hline & Constant & 0.69 & 0.21 & - & 3.24 & 0.00 & 240.86 & 0.63 & 0.40 & 0.40 & 0.67 \\
\hline & SoC & 0.33 & 0.04 & 0.30 & 8.89 & $0.00 *$ & - & - & - & - & - \\
\hline & Work-SoC & 0.52 & 0.04 & 0.42 & 12.51 & $0.00 *$ & - & - & - & - & - \\
\hline & Constant & 1.40 & 0.21 & - & 6.78 & 0.00 & 370.44 & 0.58 & 0.34 & 0.34 & 0.52 \\
\hline & Work-SoC & 0.71 & 0.04 & 0.58 & 19.10 & $0.00 *$ & - & - & - & - & - \\
\hline & Constant & 0.69 & 0.21 & - & 3.24 & 0.00 & 221.60 & 0.63 & 0.40 & 0.40 & 0.67 \\
\hline & Work-SoC & 0.52 & 0.04 & 0.42 & 12.51 & $0.00 *$ & - & - & - & - & - \\
\hline & SoC & 0.33 & 0.04 & 0.30 & 8.89 & $0.00 *$ & - & - & - & - & - \\
\hline \multirow[t]{9}{*}{ Fatigue } & Constant & 6.12 & 0.16 & - & 38.34 & 0.00 & 357.58 & 0.58 & 0.33 & 0.33 & 0.49 \\
\hline & SoC & -0.56 & 0.03 & -0.58 & -18.91 & $0.00 *$ & - & - & - & - & - \\
\hline & SoC & -0.42 & 0.03 & -0.43 & -12.64 & $0.00 *$ & - & - & - & - & - \\
\hline & Work-SoC & -0.30 & 0.04 & -0.28 & -8.17 & $0.00 *$ & - & - & - & - & - \\
\hline & Constant & 6.12 & 0.19 & - & 31.80 & 0.00 & 243.36 & 0.50 & 0.25 & 0.25 & 0.33 \\
\hline & Work-SoC & -0.54 & 0.04 & -0.50 & -15.60 & $0.00 *$ & - & - & - & - & - \\
\hline & Constant & 7.01 & 0.19 & - & 37.32 & 0.00 & 228.49 & 0.62 & 0.39 & 0.39 & 0.64 \\
\hline & Work-SoC & -0.30 & 0.04 & -0.28 & -8.17 & $0.00 *$ & - & - & - & - & - \\
\hline & SoC & -0.42 & 0.03 & -0.43 & -12.64 & $0.00 *$ & - & - & - & - & - \\
\hline
\end{tabular}

Work-SoC, Work-related sense of coherence; SE, standard error; SoC, sense of coherence. $*, p<0.05$.

\section{Determining the incremental validity of work- related sense of coherence}

Hierarchical multiple regression was used to determine if Work-SoC provided incremental variance over and above SoC in predicting work engagement and fatigue, respectively. The results are displayed in Table 4 . In step 1, only SoC was entered. In step 2, Work-SoC was added. In step 3, WorkSoC was entered first, while in step 4 , SoC was added to Work-SoC.

Table 4 indicates that both SoC and Work-SoC emerged as significant predictors of work engagement and fatigue, respectively, and when both were entered as predictors. Work-SoC predicted an additional 13\% ( $R^{2}$ change) over and above the $27 \%\left(\Delta R^{2}\right)$ that was predicted by SoC of the variance in work engagement. When Work-SoC was entered first, SoC predicted an additional $6.6 \%$ over and above the $33.5 \%$ that was predicted by Work-SoC of the variance in work engagement. Work-related sense of coherence then also predicted an additional $6 \%$ over and above the $33 \%$ that was predicted by SoC of the variance in fatigue. When Work-SoC was entered first, SoC predicted an additional 13.6\% over and above the $25 \%$ that was predicted by Work-SoC of the variance in fatigue. The percentages predicted were of large effect $\left(f^{2} \geq 0.35\right)$ except for Work-SoC predicting fatigue, which was of medium effect $\left(f^{2} \geq 0.15\right)$.

\section{Discussion}

The aim of this study was to determine whether Work-SoC provides incremental validity above and beyond that of SoC in predicting work engagement and fatigue as indicators of work wellness.

Congruent with the first hypothesis formulated, Work-SoC significantly predicted work engagement above and beyond SoC. Work-related sense of coherence also appeared to be a stronger predictor of work engagement in comparison with SoC. In line with the second hypothesis formulated, WorkSoC again predicted additional variance of fatigue over and above that of SoC. This was partially in line with the findings of Eberz et al. (2011), which showed that Work-SoC explained 
incremental variance of work-related stress. Eberz et al. (2011) also found that Work-SoC appeared to be a stronger predictor of work-related stress than SoC. The findings of the current study differed in that Work-SoC (even though providing incremental validity) was not a stronger predictor of fatigue in comparison with SoC. These results, however, do seem to corroborate earlier findings of Vogt et al. (2013) who reported that the mediating effect of Work-SoC was stronger between job resources and work engagement than between job demands and burnout. These results would suggest that Work-SoC appears to be a better predictor of work engagement than of fatigue in comparison with SoC. However, SoC seems to be a better predictor of fatigue than of work engagement in comparison with Work-SoC. From this, one could hypothesise that Work-SoC could be a stronger predictor of work wellness in the motivational, healthpromoting process, but that $\mathrm{SoC}$ could be a stronger predictor of work wellness in the energetic, health-impairment process (Bakker, Demerouti \& Schaufeli, 2003).

\section{Managerial implications and recommendations}

The work-related sense of coherence explained incremental validity of work engagement and fatigue as indicators of work wellness and could therefore be used with confidence in organisations as a context-specific application of SoC. Interventions aimed at addressing the work engagement of employees would be more suitable if they were to focus on Work-SoC as an indicator of coherent work experiences, rather than focusing on SoC. In this regard, management could consider increasing aspects like employees' understanding of their contribution to the overall goals of the organisation, job security and effective teamwork in order to address their experience of comprehensibility. Ensuring an appropriate underload-overload balance, being equipped with the relevant knowledge and skills in order to perform required tasks and experiencing social support could address employees' experience of manageability. Having discretionary freedom and being able to participate in decision-making in the work context could address the experience of meaningfulness of employees. However, if the aim of interventions is to address fatigue (as a dimension of burnout), it would seem that SoC could be a stronger predictor to take into account.

\section{Limitations}

A number of limitations of the study should be noted. A convenience sample of only one population was used and the researcher did not know in which contexts or industries these employees were working. It is therefore not possible to generalise the results of this study to other employees in South Africa. In order to limit the number of items, only the short form of SoC and a dimension of burnout, namely fatigue, were included in the data collection. The full SoC and burnout scales could be used in further studies. Future research could also investigate the degree to which WorkSoC and SoC predict other variables of work wellness in organisations, using large, random samples from a variety of industries in South Africa. The hypotheses that WorkSoC is a stronger predictor in the motivational process of work wellness and that $\mathrm{SoC}$ is a stronger predictor in the energetic process of work wellness need to be tested in other studies.

\section{Conclusion}

The study confirmed that Work-SoC provides incremental validity in predicting work engagement and fatigue over and above the variance that is predicted by SoC. This indicates that Work-SoC and SoC are interrelated but independent factors. The work-related sense of coherence appeared to be a stronger predictor of work engagement and $\mathrm{SoC}$ a stronger predictor of fatigue. The findings support the proposition of Vogt et al. (2013) that Work-SoC may be a more sensitive predictor of work wellness than general SoC.

\section{Acknowledgements Competing interests}

The author declares that she has no financial or personal relationships that may have inappropriately influenced her in writing this article.

\section{References}

Antonovsky, A. (1979). Health, stress and coping. San Francisco, CA: Jossey-Bass.

Antonovsky, A. (1987). Health promoting factors at work: The sense of coherence. In R. Kalimo, M.A. El-Batawi, \& C.L. Cooper (Eds.), Psychological factors at work and their relation to health (pp. 153-167). Geneva: World Health Organization.

Asiwe, D.N., Jorgensen, L.I., \& Hill, C. (2014). The development and investigation of the psychometric properties of a burnout scale within a South African agricultural research institution. SA Journal of Industrial Psychology, 40(1), Art. \#1194, 1-14. https://doi.org/10.4102/sajip.v40i1.1194

Bakker, A.B., Demerouti, E., \& Schaufeli, W.B. (2003). Dual processes at work in a call centre: An application of the Job Demands-Resources model. European Journal of Work and Organizational Psychology, 12(4), 393-417. https://doi.org/ 10.1080/13594320344000165

Barnard, H.A., \& Muller, H. (2012). The factor structure and reliability of a six-item sense of coherence measure. Journal of Psychology in Africa, 22(4), 39-46.

Bauer, G.F. (2010, July 11). Determinants of workplace health: Salutogenic perspective on work, organization and organizational change. In Exploring the SOC determinants for health. Paper presented at the 3rd International Research Seminar on Salutogenesis and the 3rd Meeting of the IUHPE GWG-SAL. Geneva, Switzerland.

Bauer, G.F., \& Jenny, G. (2007). Development, implementation and dissemination of occupational health management (OHM): Putting salutogenesis into practice. In S. Mclntyre \& J. Houdmont (Eds.), Occupational health psychology: European perspectives on research, education and practice (pp. 219-250). Castelo da Maia, Portugal: ISMAI.

Bauer, G.F., Vogt, K., Inauen, A., \& Jenny, G.J. (2015). Work-SoC-Entwicklung und Validierung einer Skala zur Erfassung des arbeitsbezogenen. Zeitshrift für Gesundheitpsychologie, 23(1), 20-30. https://doi.org/10.1026/0943-8149/a000132

Brossing, M., \& Sjovall, R. (2010). Ledarstilens betydelse för kreativa organisationsklimat och arbetsrelaterad känsla av sammanhang. Unpublished thesis, Lunds Universitet, Lund, Sweden.

Cohen, J. (1992). Quantitative methods in psychology: A power primer. Psychological Bulletin, 112(1), 155-159. https://doi.org/10.1037/0033-2909.112.1.155

Demerouti, E., Bakker, A.B., Vardakou, I., \& Kantas, A. (2003). The convergent validity of two burnout instruments: A multitrait-multimethod analysis. European Journal of Psychological Assessment, 19, 12-23. https://doi.org/10.1027/1015-5759. 19.1.12

Eberz, S., Becker, R., \& Antoni, C.H. (2011). Kohärenzerleben im Arbeitskontext: Ein nützliches Konstrukt für die $\mathrm{ABO}$-Psychologie? [Work-related sense of coherence: A useful construct for occupational psychology?] Zeitschrift für Arbeits- und Organisationspsychologie, 55, 115-131. https://doi.org/10.1026/0932-4089/ a000056

Feldt, T. (1997). The role of sense of coherence in well-being at work: Analysis of main and moderator effects. Work and Stress, 11(2), 134-147. https://doi.org/ 10.1080/02678379708256830

Fourie, L., Rothmann, S., \& Van de Vijver, A.J.R. (2008). A model of work wellness for non-professional counsellors in South Africa. Stress and Health, 24(1), 35-47. https://doi.org/10.1002/smi.1163 
Hair, J.F., Black, W.C., Babin, B.J., \& Anderson, R.E. (2010). Multivariate data analysis: A global perspective. Upper Saddle River, NJ: Pearson.

Jenny, G.J., Bauer, G.F., Vinje, H.F., Vogt, K., \& Torp, S. (2017). The application of Salutogenesis to work. In M.B. Mittelmark, S. Sagy, M. Eriksson, G.F. Bauer, J.M. Pelikan, B. Lindström, \& G.A. Espnes (Eds.). The handbook of salutogenesis (pp. 197-210). Cham, Switzerland: Springer.

Kalimo, R., Pahkin, K., Mutanen, P., \& Topipinen-Tanner, S. (2003). Staying well or burning out at work: Work characteristics and personal resources as long-term predictors. Work \& Stress: An International Journal of Work, Health \& Organisations, 17(2), 109-122. https://doi.org/10.1080/0267837031000149919

Mayer, C.-H., \& Krause, C. (2011). Promoting mental health and salutogenesis in transcultural organizational and work contexts. International Review of Psychiatry, 23(6), 495-500. https://doi.org/10.3109/09540261.2011.636549

Muthén, L.K., \& Muthén, B.O. (1998-2016). Mplus users' guide (7th edn.). Los Angeles, CA: Muthen \& Muthen.

Raykov, T. (1997). Estimation of composite reliability for congeneric measures. Applied Psychological Measurement, 21, 173-184. https://doi.org/10.1177/014662169 Psychological
70212006

Schaufeli, W.B., \& Bakker, A.B. (2004). Job demands, job resources, and their relationship with burnout and engagement: A multi-sample study. Journal of Organizational Behavior, 25(3), 293-315. https://doi.org/10.1002/job.248

Schaufeli, W.B., Bakker, A.B., \& Salanova, M. (2006). The measurement of work engagement with a short questionnaire: A cross national study. Educational and Psychological Measurement, 66, 701-716. https://doi.org/10.1177/001316 4405282471

Schaufeli, W.B., Leiter, M.P., Maslach, C., \& Jackson, S.E. (1996). Maslach burnout inventory: General survey (MBI-GS). In C. Maslach, S.E. Jackson, \& M.P. Leiter (Eds.). MBl-test manual (3rd edn., pp. 191-215). Palo Alto, CA: Consulting Psychologists Press.

Schaufeli, W.B., Salanova, M., González-Romá, V., \& Bakker, A.B. (2002). The measurement of engagement and burnout: A two sample confirmatory facto analytic approach. Journal of Happiness Studies, 3, 71-92. https://doi.org/ 10.1023/A:1015630930326
SPSS. (2016). SPSS 24.0 for windows. Chicago, IL: SPSS.

Van der Colff, J.J., \& Rothmann, S. (2009). Occupational stress, sense of coherence, coping, burnout and work engagement of registered nurses in South Africa. South African Journal of Industrial Psychology, 35(1), 1-10. https://doi.org/10.4102/ sajip.v35i1.423

Van der Westhuizen, S., \& Ramasodi, E. (2016). Work-related sense of coherence scale: Reliability and validity of scores in a South African sample. Journal of Psychology in Africa, 26(3), 216-220.

Van Schalkwyk, L., \& Rothmann, S. (2008). Validation of the orientation to life questionnaire (OLO) in a chemical factory. South African Journal for Industrial Psychology, 34(2), 31-39. https://doi.org/10.4102/sajip.v34i2.725

Vogt, K., Bauer, G.F., \& Jenny, G.J. (2014, June 20). Entwicklung eines indikators für gesundheitsförderliche psychosoziale Arbeitsbedingungen: Das arbeitsbezogene Kohärenzgefühl. Paper presented at the 6th Scheizerischer Kongress 'Gesundheit in der Arbeidswelt', Lausanne, Switzerland.

Vogt, K., Hakanen, J.J., Jenny, G.J., \& Bauer, G.F. (2016). Sense of coherence and the motivational process of the job-demands-resources model. Journal of Occupational Health Psychology, 21(2), 194-207. https://doi.org/10.1037/ a0039899

Vogt, K., Jenny, G.J., \& Bauer, G.F. (2013). Comprehensibility, manageability and meaningfulness at work: Construct validity of a scale measuring work-related sense of coherence. SA Journal of Industrial Psychology, 39(1), 1-8. http://doi. org/10.4102/sajip.v39i1.1111

Vogt, K., Jenny, G.J., Füllemann, D., Inaunen, A., \& Bauer, G.F. (2012, August 08). Workrelated sense of coherence as a higher-order indicator of salutogenic working conditions. Paper presented at the Health Promotion Research: An International Forum, Trondheim, Norway.

Zikmund, W.G. (2003). Business research methods (7th edn.). Mason, OH: Thomson.

Zweber, Z.M. (2014). Organizational health climate: Three facets and outcomes of relevance to organizations. Unpublished doctoral dissertation, University of Connecticut, Mansfield, USA. 